\title{
Effects of protein contents in different natural rubber latex forms on the properties of natural rubber vulcanized with glutaraldehyde
}

\author{
R. Promsung ${ }^{1}$, Y. Nakaramontri ${ }^{2}$, N. Uthaipan ${ }^{3}$, C. Kummerlöwe ${ }^{4}$, J. Johns $^{5}$, N. Vennemann ${ }^{4}$, \\ E. Kalkornsurapranee ${ }^{1^{*}}$ \\ ${ }^{1}$ Division of Physical Sciences, Faculty of Science, Prince of Songkla University, Hat-Yai, Thailand \\ ${ }^{2}$ Department of Chemistry, Faculty of Science, King Mongkut's University of Technology Thonburi, Thailand \\ ${ }^{3}$ Sino-Thai International Rubber College, Prince of Songkla University, Hat-Yai, Thailand \\ ${ }^{4}$ Faculty of Engineering and Computer Science, University of Applied Sciences Osnabrück, Osnabrück, Germany \\ ${ }^{5}$ Department of Physics, Rajarajeswari College of Engineering, Bangalore, India
}

Received 12 June 2020; accepted in revised form 10 September 2020

\begin{abstract}
This work presents a simple processing way to vulcanize natural rubber (NR) using glutaraldehyde (GA) as a curing agent at low temperature. The effect of different protein contents of NR latex on the resulting properties of the NR vulcanizates is examined in this paper. The protein contents in different NR latex, including creamed-NR (CreNR), centrifuged-NR (CenNR), and synthetic-NR (SynNR) latexes, were successfully analyzed. It was found that CreNR has the highest protein content, followed by CenNR and SynNR, respectively. The influence of protein contents in NR latex on crosslink density, mechanical properties, and thermal stability of the cured NR were investigated and compared. Temperature scanning stress relaxation (TSSR) technique was used to examine the crosslinking among GA and protein molecules, which has inter-particle interactions with NR molecular chain. This was compared with the conventional swelling experiments used in determining the swelling ratio. It is found that the mechanical properties, thermal stability, and the crosslinking density data are strongly related to the protein content in the NR latex, i.e., CreNR $>$ CenNR $>$ Syn NR. This is attributed to the protein strong contacts of the protein content to the NR chain and its ability to propagate chemical crosslinking with GA molecules. Therefore, the protein causes new linkages between rubber molecules through GA.
\end{abstract}

Keywords: rubber, natural rubber latex, protein, crosslink density, TSSR

\section{Introduction}

Natural rubber (NR) latex is a colloid system having the rubber particles dispersed in water. NR obtained from Hevea Brasiliensis is practically pure cis-1,4polyisoprene. However, NR contains a small amount of approximately 4-6\% non-rubber components, and it is well known that those exert an influence on vulcanization behavior as well as the final properties of rubber products. Figure 1 shows the schematic representation of natural rubber latex particle. Generally, rubber particles in the colloidal latex are physically linked with the molecules of non-rubber components, such as proteins, resinous matters (including lipids), hydrocarbons, and mineral substances. These non-rubber constituents, particularly proteins and lipids, surround the rubber particles and give them a negative charge assuring the latex stability [1]. In order to produce NR products, such as pillow, mattress, elastic band, glove, and condom, etc., highly concentrated rubber latex is needed as it requires higher elastic properties to make the products. Highly concentrated NR latex, typically $60 \%$ rubber particles 


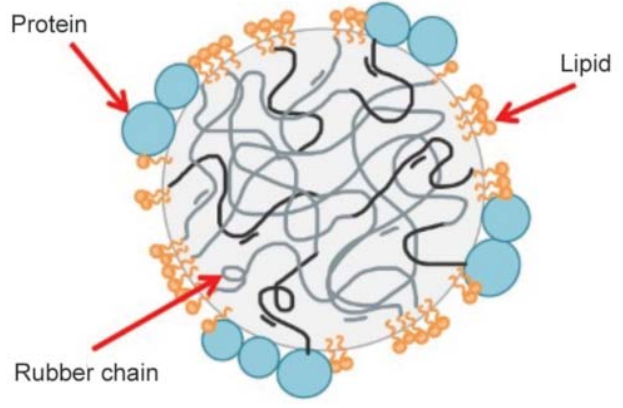

Figure 1. Natural rubber latex particle [2].

and remaining non-rubbery constituents is needed to be prepared as raw materials for producing those rubber products. It can be produced by various processes like evaporation, electrodecantation, centrifuging, and creaming [3-5].

Centrifugation technique generally refers to increase the concentration of NR latex by applying a strong centrifugal force that separates NR particles, nonrubber components, and water phases due to the difference in density between these components. In the creaming process, a creaming agent is added to NR latex for separating the NR particles phase and nonrubber components. This is an easiest and environmentally friendly technique, which consumes least power [4]. The majority of the non-rubber contents are removed during processing, but still, traces could be present in the dried rubber, particularly the nonsoluble particles $[6,7]$.

Low-temperature vulcanization of NR using glutaraldehyde (GA) as a curing agent was initially reported by Johns et al. [8]. It was found that NR can be vulcanized using GA without any specific activator and accelerator, which is highly favorable to the environment. This method is easy to process and uses less energy to prepare vulcanized rubber. It has to be noted that this curing process used only $50^{\circ} \mathrm{C}$ to vulcanize the NR molecules, whereas the general vulcanization procedures practiced use temperature over $145^{\circ} \mathrm{C}$. Crosslinking of NR with GA can be divided into two successive steps. The first step is the generation of pentane-1,5-diylidenediamine by reacting GA with ammonia existing in the latex, as shown in Figure 2. Then, in the second step, the formation of molecular chains crosslinking via the 'ene'



Figure 2. Proposed reaction mechanism of pentene-1,5-diyalidenediamine [8]. reaction between NR molecules and pentane-1,5diylidenediamine are generated in order to achieve rubber vulcanizates [8].

Recently, it was reported that GA molecules have not only reacted with ammonia, but also with the amide functional groups present on protein surfaces. Crosslinking of protein using glutaraldehyde (GA) was reported by Migneault et al. [9] and Wang et al. [10]. It was found that the GA can react with amino groups of protein by aldol condensation of GA. Moreover, Kongkaew et al. [11] studied the crosslinking of proteins in NR by treating fresh NR latex with various amounts of the GA and vulcanized with sulfur. The higher amount of proteins in treated NR accelerates the sulfur vulcanization, and the tensile strength of the vulcanizates prepared from treated NR was obviously greater than that of the vulcanizates prepared from untreated NR. Also, this was studied by Thongnuanchan et al. [12] and observed that the active ketone groups of grafted poly(diacetone acrylamide) chains could be chemically crosslinked with the aldehyde groups of GA molecules. In addition, it was proposed that the crosslinking of GA might also be reacted through amino groups $\left(\mathrm{NH}_{2}\right)$ of proteins [12]. Since the rubber particles in NR latex are stabilized by proteins, it is a challenging task to examine the effect of the protein content on the vulcanization of NR latex with GA. However, this phenomenon is still a promising challenge as a curing agent to manufacture NR by improving crosslinking.

Crosslink density is one of the most important parameters in characterizing the elastomer vulcanizates. All mechanical properties, i.e., tensile strength, modulus, and relaxation, are mainly related to the crosslink density [13]. Crosslink density can be analyzed using several techniques such as mechanical and dynamic-mechanical analysis, neutron scattering, and equilibrium swelling procedures. Another technique for the evaluation of crosslinking degrees in the rubber molecules is published in the past decade and known as 'temperature scanning stress relaxation' (TSSR). With this test, the samples were elongated to a proper strain and held for approximately $2 \mathrm{~h}$ at room temperature. During this period, short time relaxations can decay. Then, the temperature is raised at a constant rate, and the stress is continuously measured. In the initial period, the stress significantly increases owing to the entropy effect of rubbery molecular chain crosslinking. Thus, the estimation of crosslink density can be elucidated through 
the theoretical equation of Neo-Hookean according to the unfilled-rubber matrix [14]. In the past, there have been a few pieces of research that attempted to study the crosslinking in NR molecules. No work has been carried out on the crosslinking propagation in NR using GA as a crosslinking agent and taking into account the protein as an important non-rubber component. Thus, this curing is an attractive challenge for understanding and exploring the NR latex industries owing to the finding of short processing times of the final product.

In order to reach the above specific purposes, the present work is aimed to prepare three different forms of latexes, including creamed-NR (CreNR), centrifuged-NR (CenNR), and synthetic-NR (SynNR) or polyisoprene latexes. Here, the study of crosslinking propagation using GA as a curing agent was elucidated, and the possible reaction of GA and protein molecules was examined. The existence of protein inside each rubber latexes was characterized using Kjeldahl method. Mechanical, dynamical mechani$\mathrm{cal}$, and thermal properties were also investigated. In addition, the crosslinking density of each vulcanizate samples were analyzed using TSSR technique and compared with the swelling ratio measured using the conventional swelling studies.

\section{Experimental}

\subsection{Materials}

The fresh natural rubber latex (FNR) and the commercial high ammonia latex (centrifuged-NR latex, CenNR) with $60 \%$ dry rubber content $(D R C), 1.53 \%$ of non-rubber solid, $0.70 \%$ of ammonia content were purchased from Chalong Latex Industry (Songkhla, Thailand). Synthetic natural rubber (synthetic polyisoprene, SynNR) with $66.7 \%$ of $D R C$, medium particle size $(1.28 \mu \mathrm{m})$ was manufactured from Kraton Polymers Japan Co., Ltd (Tokyo, Japan). Hydroxyethylcellulose (HEC) used as a creaming agent was purchased from Brenntag Ingredients Public Company Limited (Bangkok, Thailand), and the glutaraldehyde (GA) aldehyde was purchased from Wing Great Industry Co., Ltd, (Bangkok, Thailand). Potassium laurate used as a $\mathrm{pH}$ modifier for the creaming process of the FNR purchased from Lucky Four Co., Ltd, (Bangkok, Thailand). It has to be noted that all the latexes, i.e., creamed-NR (CreNR), CenNR, and SynNR latexes, were adjusted to the total solid content (TSC) of $50 \%$. TSC was calculated by using Equation (1):
$\operatorname{TSC}[\%]=\frac{M_{1}}{M_{0}} \cdot 100$

where $M_{0}$ is the mass of the test portions [g] and $M_{1}$ is the mass of dried sheet specimen [g] with the same amount of ammonia, and the ammonia content was estimated according to ASTM D-1076-02. Approximately $5 \mathrm{~g}$ of the NR latex was poured into a beaker containing $300 \mathrm{ml}$ of double distilled water with constant stirring. $0.1 \mathrm{~mol} \mathrm{HCl}$ was slowly added until the $\mathrm{pH}$ reaches 6.0. Then, 6 drops of $0.10 \mathrm{wt} \%$ alcoholic solution of methyl red were added and titrated against $0.1 \mathrm{~mol} \mathrm{HCl}$ solution until the indicator turned to pink. The total alkalinity was calculated and reported as $\mathrm{NH}_{3}$ based on grams of $\mathrm{NH}_{3}$ per $100 \mathrm{~g}$ of latex as following the Equation (2) [15]:

Total alkalinity $\left(\right.$ as $\left._{3}\right)[\%]=\frac{1.7 \cdot M \cdot n}{W} \cdot 100$

where $M$ is the molarity of the standard $\mathrm{HCl}$ solution, $n$ is the volume of standard $\mathrm{HCl}$ required [ml], and $W$ is the original mass of the latex [g].

\subsection{Preparation of the creamed-NR latex (CreNR)}

The CreNR was prepared from FNR by using hydroxyethyl cellulose (HEC) as a creaming agent which dissolved in deionized water to $1 \%(\mathrm{w} / \mathrm{w})$. Then, $81 \mathrm{~g}$ of HEC and $4 \mathrm{~g}$ of $20 \%(\mathrm{w} / \mathrm{w})$ potassium laurate were added to the FNR $500 \mathrm{~g}$ with continuous mechanical stirring for $30 \mathrm{~min}$. The mixture was then incubated for at least $24 \mathrm{~h}$ at room temperature until the phase separation of latex and aqueous serum was distinguished. The CreNR was finally extracted from the mixture for further investigation. The percentages of TSC and DRC of CreNR latex were evaluated after incubating for $24 \mathrm{~h}$. It was found that the $\%$ TSC increases from 44.84 to $57.78 \%$, and the $\% D R C$ increases from 37.92 to $53.79 \%$.

\subsection{Preparation of latex vulcanizates using GA}

A $12.5 \%$ GA solution in deionized water was slowly added into the latexes and mechanically stirred at $50 \mathrm{rpm}$ for approximately $1 \mathrm{~min}$ at room temperature. Here, a molar ratio of ammonia:GA (2:1) was maintained in the entire investigation. This is the optimum condition to obtain pentane-1,5-diylidenediamine crosslinked rubber molecules according to the chemical reaction, as reported in our previous work $[16,17]$. The latex-GA mixture was then cast into 
the glass plate of $130 \times 130 \times 2 \mathrm{~mm}^{3}$ before drying in a hot air oven at $50^{\circ} \mathrm{C}$ for at least $24 \mathrm{~h}$ until a constant weight was reached $[16,17]$. The latex vulcanizates were finally removed and kept in the desiccator for another $24 \mathrm{~h}$ before performing the characterization.

\section{Characterization}

\subsection{Total nitrogen content}

The total nitrogen content in CreNR, CenNR and SynNR latexes with the same TSC and ammonia without GA was measured using Kjeldahl method according to Association of Official Analytical Chemists (AOAC) and Official Methods of Analysis of Fertilizers (OMAF) [18]. Here, approximately $0.1 \mathrm{~g}$ of latex samples were mixed with a catalyst mixture of $0.65 \mathrm{~g}$ (potassium sulphate: copper sulphate pentahydrate: selenium $=15: 2: 1$ weight ratio) before digesting in the concentrated sulfuric acid (conc. $\mathrm{H}_{2} \mathrm{SO}_{4}$ ). The acidic mixtures were then diluted with $50 \mathrm{ml}$ of sodium hydroxide solution $(67 \mathrm{wt} \% \mathrm{NaOH})$. After dilution, the mixtures were steam heated, and the condensation reaction was performed through the $50 \mathrm{ml}$ of $4 \mathrm{wt} \%$ boric acid solution $\left(\mathrm{H}_{3} \mathrm{BO}_{3}\right)$. Finally, the obtained solution was titrated with $0.1 \mathrm{~N}$ $\mathrm{H}_{2} \mathrm{SO}_{4}$ for examining the ammonia content in the solution, which further allows the calculation of the nitrogen content by multiplying nitrogen content with 6.25 [19].

\subsection{Attenuated total reflectance-Fourier transform infrared (ATR-FTIR)}

The ATR-FTIR spectra were recorded by the Nicolet 6700 FTIR spectrometer (Thermo Scientific Inc., Massachusetts, USA) over a wide range of wavenumber $4000-650 \mathrm{~cm}^{-1}$ with a resolution of $4 \mathrm{~cm}^{-1}$ and 32 scans. The instrument was equipped with a germanium ATR crystal probe.

\subsection{Mechanical properties}

The tensile testing of latex vulcanizates was performed using a universal testing machine (model H10KS, Hounsfield, UK). The tests were performed with a crosshead speed of $500 \mathrm{~mm} / \mathrm{min}$ at room temperature using dumbbell-shaped specimens according to ASTM D412. In case of hardness, the samples were tested using a Shore A durometer (Frank GmbH, Hamburg, Germany) as per ASTM D2240.

\subsection{Swelling measurement}

The swelling measurements of the latex vulcanizates were elucidated by soaking the specimen pieces of $10 \times 10 \times 2 \mathrm{~mm}^{3}$ in toluene in a closed system for $24 \mathrm{~h}$ at room temperature. The samples were weighed before and after soaking. The degree of swelling was calculated by using Equation (3):

Change in weight $[\%]=\frac{W_{\mathrm{s}}-W_{0}}{W_{0}} \cdot 100$

where $W_{0}$ and $W_{\mathrm{s}}$ are the weights of the specimen before and after immersions in the test liquid, respectively.

\subsection{Thermal properties}

Thermogravimetric analysis (TGA) (Mettler Toledo AG, Greifensee, Switzerland) was adopted to evaluate the thermal stability of the vulcanizates. A small amount of approximately $10 \mathrm{mg}$ of the vulcanizate was weighted in a crucible and placed inside the TGA chamber. Analysis was performed for the testing conditions of $40-600^{\circ} \mathrm{C}$ with a heating rate of $10^{\circ} \mathrm{C} / \mathrm{min}$ in nitrogen atmosphere. During the test, the samples were held at $600^{\circ} \mathrm{C}$ for $10 \mathrm{~min}$ before continuing the heating to $800^{\circ} \mathrm{C}$ under oxygen flow, and until the measurements are completed.

\subsection{Temperature scanning stress relaxation (TSSR)}

The TSSR technique (Brabender GmbH Duisburg, Germany) was used to determine the thermal-mechanical properties and crosslink density of vulcanizates. The measurements were performed using the dumbbell-shaped specimens following the ISO527 type 5A. During the test, the specimens were initially strained for $100 \%$ and pre-conditioned for $2 \mathrm{~h}$ at room temperature in order to decay the short-termed stress history of the samples in isothermal conditioning. Then, the non-isothermal heating was done by raising the temperature from $23-220^{\circ} \mathrm{C}$ with a constant heating rate of $2^{\circ} \mathrm{C} / \mathrm{min}$. Further, the relaxation force as a function of temperature was plotted. It is noted that the $T_{\mathrm{x}}$ indicates the temperature at which force has been reduced to $x \%$ relative to the observed initial force. This assists in examining the degree of the thermal resistance of the vulcanizates. In order to clarify the molecular phenomenon, the relaxation spectrum $(H(T))$ was plotted with respect to the temperature. 
Here, the relaxation force was converted to the relaxation modulus $(E(T))$ that is observed from the constant heating rate $(v)$. Therefore, using Equation (4), the $H(T)$ was calculated by differentiating $E(T)$ with respect to temperature $(T)$ as follows [20]:

$$
H(T)=-T \cdot\left(\frac{\mathrm{d} E(T)}{\mathrm{d} T}\right)_{\nu=\text { const. }}
$$

For the calculation of crosslinking density, the initial increase of curves of force versus temperature has been evaluated. At the beginning of the non-isothermal stress relaxation, the slope of the force-temperature curve is positive due to the entropy elasticity of the rubber. While at a certain stretch ratio $(\lambda)$ the thermoelastic inversion occurs. Thus, the coefficient temperature ( $\kappa$ ) becomes a negative value [13]. The coefficient of the vulcanizate during rising temperature is defined as the derivative of relaxation stress $(\sigma)$ as a function of the temperature detected by the TSSR (Equation (5)). Therefore, relating to the theory of rubber elasticity, $\sigma$ is proportional to the absolute temperature $(T)$, and can be expressed, as shown in Equation (6) [13]:

$$
\begin{aligned}
& \kappa=\left(\frac{\partial \sigma}{\partial T}\right)_{\lambda, \rho} \\
& \sigma=\frac{\rho \cdot R \cdot T}{M_{\mathrm{c}}}\left(\lambda-\lambda^{-2}\right)
\end{aligned}
$$

where $\rho$ is the mass density, and $R$ is the universal gas constant. The parameter $M_{\mathrm{c}}$ is defined as the average molar mass of the elastically active network chains. The latter factor is directly proportional to the reciprocal value of the crosslink density $(v)$ of the elastomeric network. Hence, at a constant stretch ratio, the $v$ value of the vulcanizate can be estimated from the slope of stress/versus temperature plots based on TSSR measurements [8]. Therefore, replacing the combination of Equations (5) and (6), $v$ can be calculated from the experimentally obtained value of the temperature coefficient $(\kappa)$ using the following Equation (7) [13]:

$$
v=\frac{\kappa}{R \cdot\left(\lambda-\lambda^{-2}\right)}, \text { with } v=\frac{\rho}{M_{\mathrm{c}}}
$$

\section{Results and discussion}

\subsection{Protein content of latexes}

Figure 3 exhibits the protein content estimated by detecting the amino functional groups and calculated

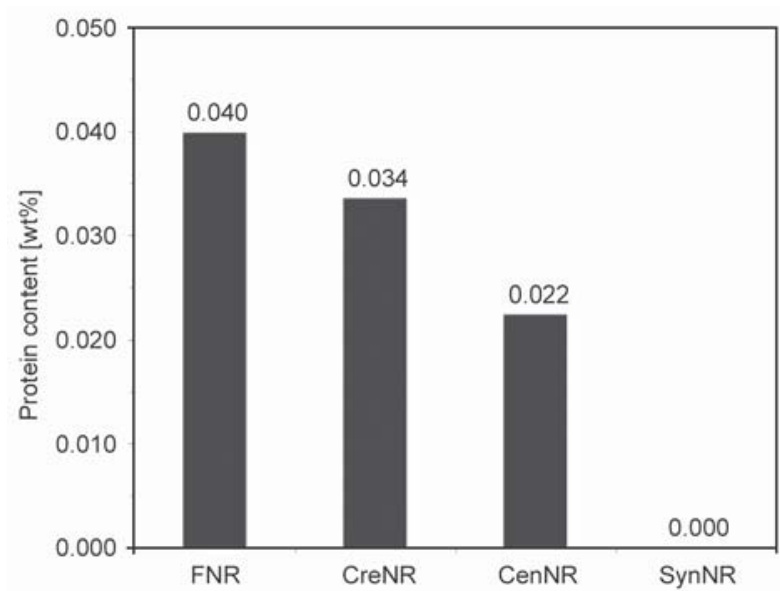

Figure 3. The protein contents of FNR, CreNR, CenNR and SynNR latexes without GA.

through the Kjeldahl method in order to evaluate the protein content in each latex. It was observed that the FNR, CreNR, CenNR and SynNR showed the results of $0.040,0.034,0.022$, and $0.000 \mathrm{wt} \%$, respectively. This means that the creaming and centrifuging processes decreased the soluble non-rubber component in the FNR significantly, particularly the centrifuging process. Here, in order to obtain CenNR, centrifugation with high-frequency vibration at $19000 \mathrm{rpm}$ [21] was applied to the FNR for separating NR particles into the liquid phase. Thus, along with the soluble constituents, smaller rubber particles, and other protein types present in serum and lutoid were also eliminated [3]. This is the reason for the lowest protein content in NR, relative to CreNR and FNR. Furthermore, SynNR has no nitrogen, as expected [22, 23].

\subsection{Origination of crosslinking among rubber molecules}

The formation of crosslinks in the latex vulcanized with GA has been confirmed by comparing the ATR-FTIR spectra of the un-vulcanized sample, as shown in Figure 4. Also, Table 1 summarizes the absorption peaks of the samples. It is found that the absorption at 2924, 1670,1446, and $831 \mathrm{~cm}^{-1}$ corresponding to $-\mathrm{C}-\mathrm{H}$ stretching vibrations, $-\mathrm{C}=\mathrm{C}$ stretching vibrations, $-\mathrm{C}-\mathrm{H}$ bending vibrations, and $-\mathrm{C}-\mathrm{H}$ out of plane bending vibrations of NR, respectively. After GA vulcanization, the new peaks appeared at $1090-1020$ and $1558 \mathrm{~cm}^{-1}$ corresponding to $-\mathrm{C}-\mathrm{N}$ stretching and $-\mathrm{N}-\mathrm{H}$ bending vibrations of a secondary amine, respectively, which are originated from the ene reaction [8]. It clearly confirms the crosslinking of NR molecules 


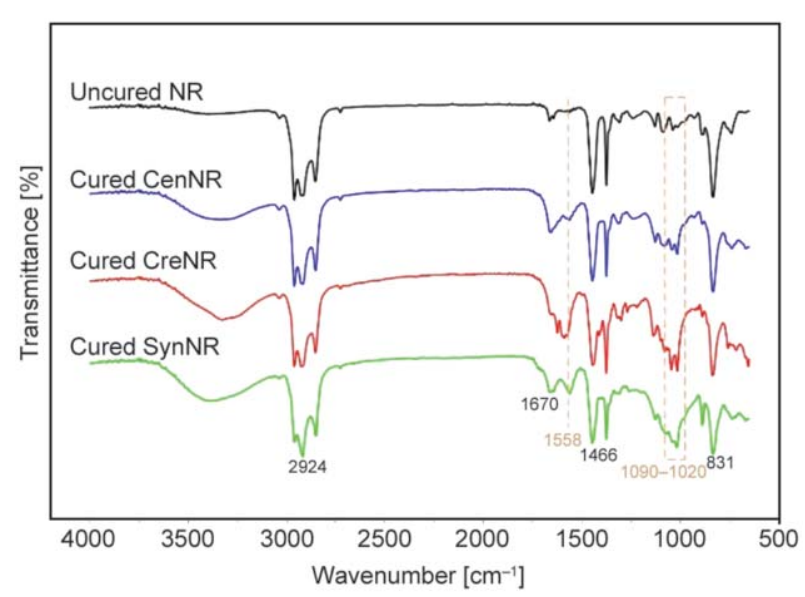

Figure 4. The ATR-FTIR spectra of uncured NR and cured NRs.

Table 1. The absorption peaks of vibrations in uncured NR and cured NRs.

\begin{tabular}{|c|l|}
\hline $\begin{array}{c}\text { Wavenumber } \\
{\left[\mathbf{c m}^{-\mathbf{1}}\right]}\end{array}$ & \multicolumn{1}{c|}{ Assignments } \\
\hline 831 & $-\mathrm{C}-\mathrm{H}$ out of plane bending vibrations of NR \\
\hline $1090-1020$ & $-\mathrm{C}-\mathrm{N}$ stretching vibrations of a secondary amine \\
\hline 1446 & $-\mathrm{C}-\mathrm{N}$ bending vibrations of NR \\
\hline 1558 & $-\mathrm{N}-\mathrm{H}$ bending vibrations of a secondary amine \\
\hline 1670 & $-\mathrm{C}=\mathrm{C}$ stretching vibrations of NR \\
\hline 2924 & $-\mathrm{C}-\mathrm{H}$ stretching vibrations of NR \\
\hline
\end{tabular}

with pentane-1,5-diylidenediamine by ene reaction.

The crosslinking propagation in the latex vulcanized with GA is elucidated through the mechanical properties in terms of tensile strength, elongation at break, $100-500 \%$ moduli, and hardness of the CreNR, CenNR and SynNR vulcanizates. Figure 5 shows the stress-strain curves of each latex vulcanizate and non-vulcanized SynNR following the ASTM D412. Also, Table 2 summarizes the observed values of all vulcanizates. Different stress behaviors during straining are distinguished; for strain lower than 5\%, the latex vulcanizates showed the increase of stress following the Neo-Hookean theory. This is due to the chain entanglement of rubber molecules, which resists the extension of the samples. In addition, after $1 \mathrm{MPa}$ of SynNR was reached, the superior stress as a function of the strain of CreNR and CenNR still increased continuously to approximately $2.5 \mathrm{MPa}$ (in Figure 5a). This might be due to the crosslinking based on the chemical reaction between GA, ammonia, and rubber molecules, as shown in the proposed model depicted in Figure 6a. On the other hand, the uncured SynNR sample exhibited an increase in tensile stress from 0.40 to $1.12 \mathrm{MPa}(64.3 \%$ increase $)$, and the tensile strain increases from 574 to $2210 \%$ (74.03\% increase) on curing SynNR as shown in Figure $5 \mathrm{~b}$. This is well correlated with our previous work that proved the possible crosslinking ene-reaction under low temperature. However, having the same content of ammonia in all the latex used, the highest increase of stress for CreNR might be attributed to the combination of crosslinking propagation of GA with ammonia and GA with amino groups in protein. For the model shown in Figure 6b, it is proposed that the GA molecules react with the amino groups of protein, resulting in Protein-GA-Protein chemical linkages. These linkages are connected to rubber molecules through the 'inter-particle crosslinks', which further increases the total crosslink density of the vulcanizate [12]. This phenomenon is also evident in the CenNR, which has lower protein content than the CreNR as shown in Figure 3. In Figure 5 and Table 2, the higher crosslink density is observed in CreNR and CenNR, which results in better tensile strength and 100-500\% moduli as compared to SynNR. This is due to the fact that SynNR has no protein content and the processes of preparing SynNR and NR latex are totally different. SynNR latex is synthetic latex synthesized via emulsion polymerization and using long-chain soap as preservation, hence decreasing the stress against strain during extension propagation. It is noted that the increase in elongation at break of SynNR is due to the presence of fewer crosslinks and the occurrence of molecular chain slippages because of the less chemical restrictions among the molecules [24]. The effect of different protein contents on the mechanical properties is

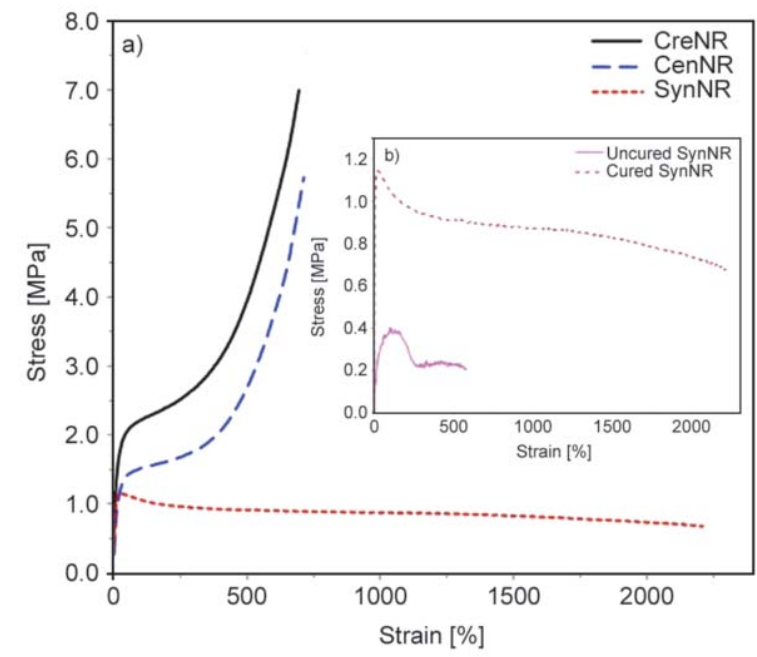

Figure 5. The stress-strain curves of the samples, (a) CreNR, CenNR and SynNR vulcanizates and (b) uncured and cured SynNR. 
Table 2. Protein contents and mechanical properties of CreNR, CenNR and SynNR vulcanizates.

\begin{tabular}{|l|c|c|c|c|c|c|}
\hline Samples & $\begin{array}{c}\text { Protein content } \\
{[\%]}\end{array}$ & $\begin{array}{c}\mathbf{1 0 0 \%} \text { modulus } \\
{[\mathbf{M P a}]}\end{array}$ & $\begin{array}{c}\mathbf{3 0 0 \%} \text { modulus } \\
{[\mathbf{M P a}]}\end{array}$ & $\begin{array}{c}\mathbf{5 0 0 \%} \text { modulus } \\
{[\mathbf{M P a}]}\end{array}$ & $\begin{array}{c}\text { Tensile strength } \\
{[\mathbf{M P a}]}\end{array}$ & $\begin{array}{c}\text { Hardness } \\
\text { [Shore A] }\end{array}$ \\
\hline CreNR & 0.034 & $2.27 \pm 0.13$ & $2.70 \pm 0.11$ & $3.87 \pm 0.90$ & $6.72 \pm 0.40$ & $59.00 \pm 2.77$ \\
\hline CenNR & 0.022 & $1.51 \pm 0.03$ & $1.76 \pm 0.01$ & $2.68 \pm 0.05$ & $5.70 \pm 0.03$ & $51.00 \pm 3.60$ \\
\hline SynNR & 0.000 & $1.03 \pm 0.07$ & $0.92 \pm 0.06$ & $0.88 \pm 0.06$ & $1.12 \pm 0.07$ & $50.00 \pm 2.73$ \\
\hline
\end{tabular}

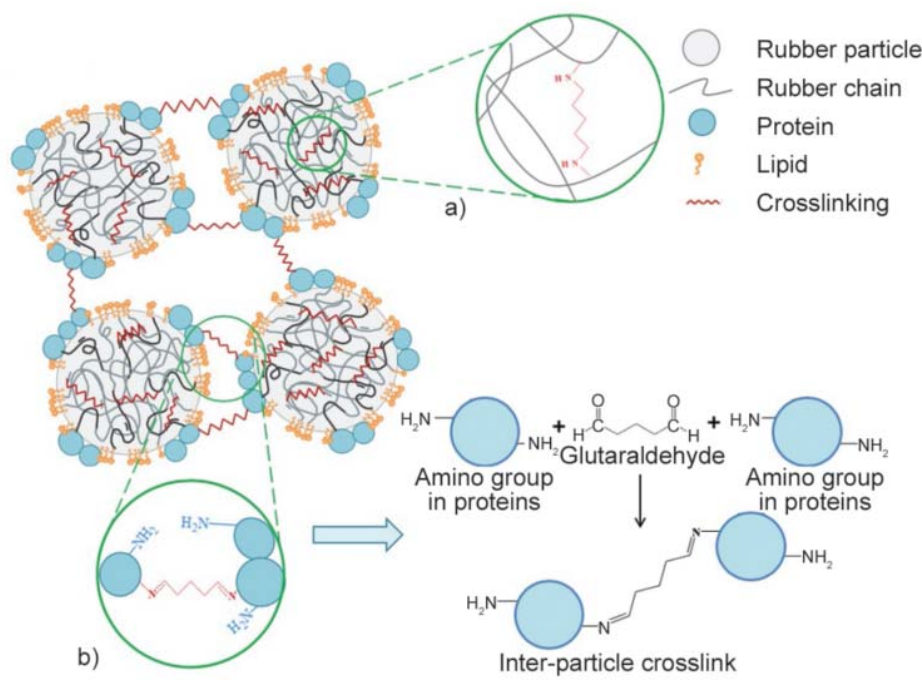

Figure 6. Proposed model of crosslinking of the vulcanizates by GA (a) the ene-reaction linkages (b) the Protein-GA-Protein linkages.



Figure 7. Modulus and tensile strength of the CreNR $(0.034 \mathrm{wt} \%)$, CenNR $(0.022 \mathrm{wt} \%)$ and SynNR $(0.000 \mathrm{wt} \%)$ vulcanizates. represented in Figure 7. It is clearly seen that the tensile strength and modulus of the latex vulcanizate increases with the amount of protein content in the latex.

In order to clarify the existence of chemical crosslinking in the latex vulcanizates having different protein contents and using GA as a curing agent, the swelling ratio observed from the swelling studies, and crosslink density observed from TSSR studies of the vulcanizates are shown in Table 3. It is quite evident that the swelling ratio and crosslink density of different latexes showed a strong correlation. Here, it was not possible to detect the crosslink density of SynNR as there is only rare crosslinking propagation in the sample as seen from the stress-strain curve. Considering the CreNR and CenNR, it can be confirmed that the crosslink density of the latex

Table 3. Crosslink densities and thermal stability limits of CreNR, CenNR and SynNR vulcanizates obtained from the TSSR together with swelling studies.

\begin{tabular}{|c|c|c|c|c|c|c|c|}
\hline \multirow[b]{2}{*}{ Samples } & \multicolumn{6}{|c|}{ TSSR measurement } & \multirow{2}{*}{$\begin{array}{c}\text { Swelling measurement } \\
\text { Swelling ratios } \\
{[\%]}\end{array}$} \\
\hline & $\begin{array}{c}\sigma_{0} \\
{[\mathrm{MPa}]}\end{array}$ & $\begin{array}{c}T_{10} \\
{\left[{ }^{\circ} \mathrm{C}\right]}\end{array}$ & $\begin{array}{c}T_{50} \\
{\left[{ }^{\circ} \mathrm{C}\right]}\end{array}$ & $\begin{array}{c}T_{90} \\
{\left[{ }^{\circ} \mathrm{C}\right]}\end{array}$ & $\begin{array}{c}\mathbf{K}_{0} \\
{[\mathrm{~Pa} / \mathrm{K}]}\end{array}$ & $\begin{array}{c}\text { Crosslink density } \\
{\left[\mathrm{mol} / \mathrm{m}^{3}\right]}\end{array}$ & \\
\hline CreNR & 0.89 & 46.4 & 74.3 & 143.0 & 1331.4 & 91.5 & 505.34 \\
\hline CenNR & 0.84 & 46.8 & 73.3 & 145.4 & 1058.4 & 72.4 & 683.42 \\
\hline SynNR & $-^{*}$ & $-^{*}$ & $-^{*}$ & $-^{*}$ & $-^{*}$ & $-^{*}$ & $-^{* *}$ \\
\hline
\end{tabular}

*SynNR sample was breaking during isothermal testing

${ }^{* *}$ SynNR samples were dissolved in toluene 
increased with an increasing protein content as the CreNR showed higher value than the CenNR with a lower degree of swellability. As expected, this is due to the inter-particle crosslinks occurred between GA molecules and proteins, as proposed in the model shown in Figure 6b.

\subsection{Temperature scanning stress relaxation (TSSR)}

TSSR is a recent technique developed by Vennemann et al. [13], and Chatterjee et al. [25] for interpreting the behavior of rubbery molecular chain by reporting the stress relaxation as a function of temperature under a constant heating rate. In order to perform this test, the isothermal and non-isothermal relaxation processes were taken into account. From the TSSR results, the initial stress, crosslinking density, the interaction of rubber and protein molecules (see reaction above), and thermal stability were examined. Figure 8 shows the relation of the normalized force against the temperature provided by TSSR measurement. Here, the measurement for the SynNR was abandoned as the sample was breaking beyond $50^{\circ} \mathrm{C}$, due to the fact that there are weakly chemical crosslinking within this type of latex. Considering the TSSR curves of CreNR and CenNR, it is seen that three different regions of the normalized force are exhibited. For the temperature range of $23-30{ }^{\circ} \mathrm{C}$, the force increases with increasing temperature. This could be explained by the entropy effect of the rubber vulcanizates. Without chemical crosslinks, the force would be decreasing with rising temperatures. The initial increase that appeared in the curves of force versus temperature has been used to evaluate the

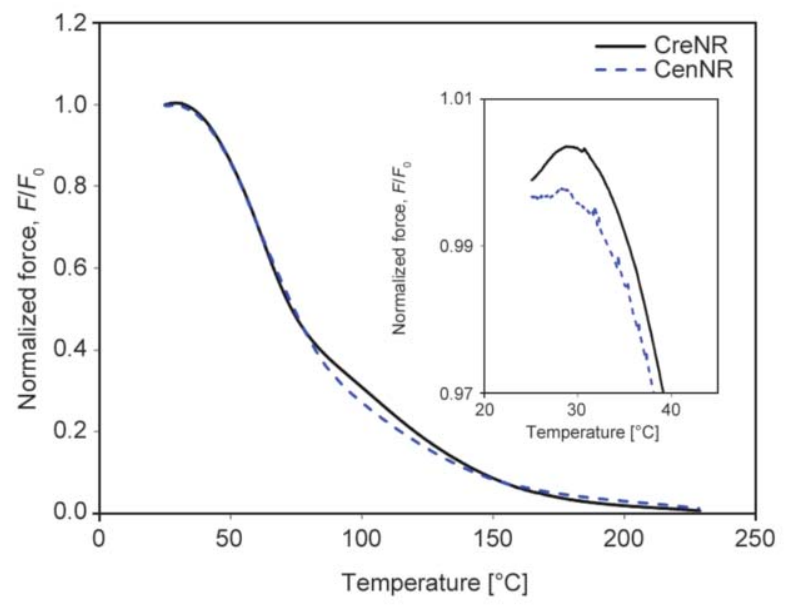

Figure 8. The normalized force as a function of temperature of CreNR and CenNR vulcanizates obtained from TSSR. crosslink density. In this region, the crosslink density (v) of each vulcanizate obtained from the experimental software can be calculated using Equation (7), and the results are summarized in Table 3 . The higher initial stress and coefficient $\left(\kappa_{0}\right)$ values of CreNR samples showed higher $v$ values compared to CenNR. Also, the value of swelling ratio obtained from swelling studies in the case of CreNR showed a slightly lower value than that of CenNR. It correlates well with the crosslink density obtained from the TSSR measurement (Table 3). This confirms the origination of crosslinking reaction inside the CreNR and CenNR by the GA molecules with ammonia and NR and with amino groups present in proteins. The thermal stability obtained from the normalized forcetemperature from Figure 8 is depicted in Table 3. Also, it summarizes the temperature at which the normalized force decreased to 10,50 , and $90 \%\left(T_{10}\right.$, $T_{50}$, and $T_{90}$ ). It is observed here that the CreNR showed slightly lower degradation temperature than CenNR, which might be due to the higher amount of independent protein-crosslinked GA linkages in CreNR than CenNR, since these linkages are detached from the NR molecules, and the thermal stability caused by the crosslinking with NR molecules is therefore decreased.

Considering the peak in the temperature range of 30$90^{\circ} \mathrm{C}$, as shown in Figures 8 and 9, CreNR exhibited a broader peak than that of CenNR. This peak is attributed to the de-bonding of branching in latex caused by the hydrogen bonding of protein molecules and $\omega$-terminal group, also ionic bonding of phospholipids and $\alpha$-terminal group in NR molecules, respectively [26]. The broad peak in CreNR

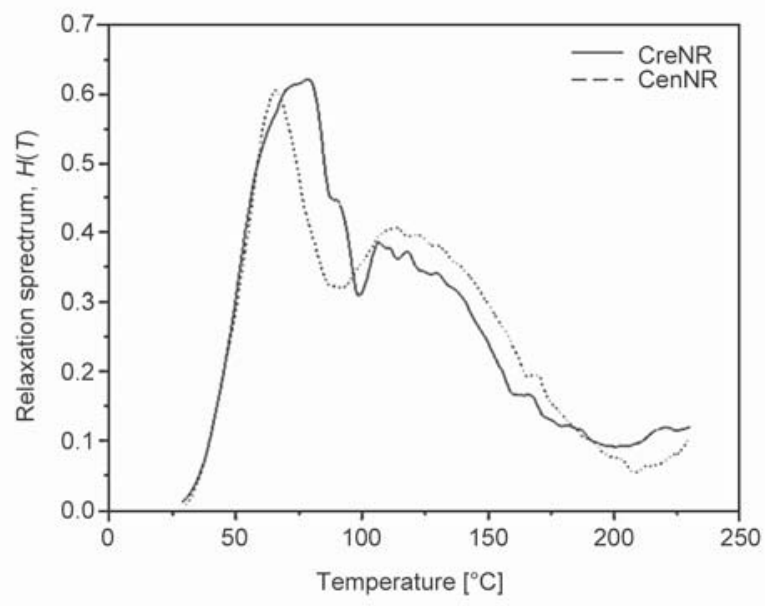

Figure 9. The relaxation spectrum as a function of temperature of CreNR and CenNR vulcanizates obtained from TSSR. 
might be due to a higher amount of proteins relative to CenNR (see in Figure 3). This means that the protein-crosslinked GA linkages have independently dispersed and distributed throughout the latex matrices without inter-particle attraction to NR. The last region of decomposition detected from the TSSR beyond $10{ }^{\circ} \mathrm{C}$ is due to the thermo-oxidative decomposition of the NR molecules under stress. In order to clarify the state of decomposition of the latex vulcanizate, the relaxation spectrum, which is the differential of stress relaxation curve, is shown in Figure 9.

\subsection{Thermal resistance without extension}

The thermal stability of CreNR, CenNR, and SynNR vulcanizates was characterized using the TGA, as shown in Figure 10. Also, the decomposition degrees of each vulcanizate are summarized in Table 4 in terms of onset decomposition temperature $\left(T_{0}\right)$, the maximum rate of decomposition temperature $\left(T_{\mathrm{p}}\right)$, and the termination decomposition temperature $\left(T_{\mathrm{f}}\right)$. The decomposition temperature $\left(T_{\mathrm{p}}\right)$ of CreNR, CenNR, and SynNR vulcanizates was found to be higher than pure $\mathrm{NR}\left(T_{\mathrm{p}}=352^{\circ} \mathrm{C}\right)$ as reported in the previous work [27]. It was found that the decomposition temperature $\left(T_{0}\right.$ and $\left.T_{\mathrm{f}}\right)$ of CreNR slightly lower than CenNR as found in the TGA results. The scission and crosslinking occur in rubber at the temperature range of $200-270^{\circ} \mathrm{C}$. NR undergoes thermal degradation in the temperature range of $287-400^{\circ} \mathrm{C}$ by generating $39 \%$ isoprene, $13.2 \%$ dipentene, and small amounts of $p$-menthene. Dipentene is the major degradation product in the temperature range of $450-800^{\circ} \mathrm{C}$, and isoprene is the major degradation



Figure 10. The TGA thermograms of CreNR, CenNR and SynNR vulcanizates.
Table 4. Thermal properties of CreNR, CenNR and SynNR vulcanizates measured from TGA.

\begin{tabular}{|c|c|c|c|}
\hline Samples & $\begin{array}{c}\boldsymbol{T}_{\mathbf{0}} \\
{\left[{ }^{\circ} \mathbf{C}\right]}\end{array}$ & $\begin{array}{c}\boldsymbol{T}_{\mathbf{p}} \\
{\left[{ }^{\circ} \mathbf{C}\right]}\end{array}$ & $\begin{array}{c}\boldsymbol{T}_{\mathbf{f}} \\
{\left[{ }^{\circ} \mathbf{C}\right]}\end{array}$ \\
\hline CreNR & 219.32 & 386.38 & 605.70 \\
\hline CenNR & 221.41 & 385.30 & 609.72 \\
\hline SynNR & 206.46 & 355.14 & 404.20 \\
\hline
\end{tabular}

product in the temperature range of $675-800^{\circ} \mathrm{C}$ [8]. This is attributed to the dislocation of the inter-particles crosslinking of the rubber. Here, increasing the heat during testing eliminated the chemical crosslink of GA between rubber-rubber molecules and also amino groups present in protein molecules. However, in the case of SynNR, poor decomposition temperature is occurred owing to their lack of chemical crosslinking originated by the GA molecules in the latex. Therefore, it can be summarized that using GA for vulcanizing NR molecular chain is succeeded by two different possibilities: (I) GA with ammonia and NR molecules and (II) GA with amino groups present in protein molecules which have a strong interparticles attraction with NR molecules. This is affirmed by FTIR spectra (Figure 4 and Table 1), the improved mechanical properties (Figures 5 and 7 , Table 2), crosslinking density (Table 3 ) and thermal stability (Figure 10, Tables 3 and 4 ) and also the observed molecular chains phenomena based on the TSSR measurements (Figures 8 and 9).

\section{Conclusions}

Different forms of NR latex with different protein contents i.e, CreNR $>$ CenNR $>$ SynNR were successfully prepared. The properties in terms of mechanical and dynamic mechanical properties, crosslink density, and thermal stability of NR latex cured with GA were effectively improved related to the protein contents in NR. This caused the CreNR, which has the highest protein content, also had the highest NR properties with superior modulus. Also, according to the TSSR results, the estimated crosslink density and thermal stability during mechanical nonisothermal attraction were elucidated. It was affirmed clearly that the CreNR showed significant improvement in the results due to strong contacts with the NR chain and its ability to propagate chemical crosslinking with GA molecules. This related well to the TGA thermogram. Therefore, it can be summarized that the NR vulcanizations were carried out at a low curing temperature. The vulcanized NR exhibited several superior properties related to the existing 
protein. This can be definitely introduced in various industrial applications by using low-temperature vulcanization, which enhances modulus, thermal stability, and strength at a lower strain. Also, the research related to new genetic engineering of the NR tree should be focused more on increasing the protein content.

\section{Acknowledgements}

This study was supported by research grants from the Royal Golden Jubilee (RGJ) Ph.D. Program (grant no. PHD/ 0180/2561), the Thailand Research Fund (TRF). The authors also would like to express their gratitude to the Faculty of Science, Prince of Songkla University, Hat Yai Campus. Regarding German collaborators, we gratefully acknowledge the facility support from the Faculty of Engineering and Computer Science, University of Applied Sciences Osnabrück, Germany. The authors also would like to thank the Innolatex (Thailand) Co., Ltd., Thailand for supporting the synthetic polyisoprene latex and King Mongkut's University of Technology Thonburi for the technical supports. Thanks to Miss Natália Coppi Manica for her kind help in the Thermogravimetric analysis characterization part.

\section{References}

[1] Berthelot K., Lecomte S., Estevez Y., Zhendre V., Henry S., Thévenot J., Dufourc J. E., Alves D. I., Peruch F.: Rubber particle proteins, HbREF and HbSRPP, show different interactions with model membranes. Biochimica et Biophysica Acta (BBA) - Biomembranes, 1838, 287-299 (2014).

https://doi.org/10.1016/j.bbamem.2013.08.025

[2] Wei Y., Zhang H., Wu L., Jin L., Liao S.: A review on characterization of molecular structure of natural rubber. MOJ Polymer Science, 1, 197-199 (2017). https://doi.org/10.15406/mojps.2017.01.00032

[3] Duckworth I. H.: Creamed latex concentrate. Rubber Chemistry and Technology, 38, 233-242 (1965). https://doi.org/10.5254/1.3535643

[4] Suksup R., Imkaew C., Smitthipong W.: Cream concentrated latex for foam rubber products. IOP Conference Series: Materials Science and Engineering, 272, 12-25 (2017). https://doi.org/10.1088/1757-899x/272/1/012025

[5] Murphy E. A.: Electrodecantation for concentrating and purifying latex. Rubber Chemistry and Technology, 16, 529-535 (1943). https://doi.org/10.5254/1.3540137

[6] Mathew S., Varghese S.: Extractable proteins in latex products: Effect of vulcanization methodsand leaching. Rubber Science, 31, 249-258 (2018).
[7] Ochigbo S., Lafia-Araga R., Suleiman M.: Comparison of two creaming methods for preparation of natural rubber latex concentrates from field latex. African Journal of Agricultural Research, 6, 2916-2919 (2011). https://doi.org/10.5897/AJAR10.1173

[8] Johns J., Nakason C., Thitithammawong A., Klinpituksa P.: Method to vulcanize natural rubber from medium ammonia latex by using glutaraldehyde. Rubber Chemistry and Technology, 85, 565-575 (2012). https://doi.org/10.5254/rct.12.88920

[9] Migneault I., Dartiguenave C., Bertrand M. J., Waldron K. C.: Glutaraldehyde: Behavior in aqueous solution, reaction with proteins, and application to enzyme crosslinking. BioTechniques, 37, 790-802 (2004). https://doi.org/10.2144/04375RV01

[10] Wang Y., Mo X., Sun X. S., Wang D.: Soy protein adhesion enhanced by glutaraldehyde crosslink. Journal of Applied Polymer Science, 104, 130-136 (2007).

https://doi.org/10.1002/app.24675

[11] Kongkaew C., Poonsrisawat A., Champreda V., Loykulnant S.: Maillard reaction in natural rubber latex: Improvement of concentration process. Journal of Applied Polymer Science, 134, 45224/1-45224/7 (2017). https://doi.org/10.1002/app.45224

[12] Thongnuanchan B., Ninjan R., Kalkornsurapranee E., Lopattananon N., Nakason C.: Glutaraldehyde as ambient temperature crosslinking agent of latex films from natural rubber grafted with poly(diacetone acrylamide). Journal of Polymers and the Environment, 26, 30693085 (2018).

https://doi.org/10.1007/s10924-018-1193-8

[13] Vennemann N., Bökamp K., Bröker D.: Crosslink density of peroxide cured TPV. Macromolecular Symposia, 245-246, 641-650 (2006).

https://doi.org/10.1002/masy.200651391

[14] Nakaramontri Y., Kummerlöwe C., Vennemann N., Wisunthorn S., Pichaiyut S., Nakason C.: Electron tunneling in carbon nanotubes and carbon black hybrid filler-filled natural rubber composites: Influence of nonrubber components. Polymer Composites, 32, 12371250 (2018). https://doi.org/10.1002/pc.24821

[15] Johns A., Aan M. P. S., Johns J., Bhagyashekar M. S., Nakason C., Kalkornsurapranee E.: Optimization study of ammonia and glutaraldehyde contents on vulcanization of natural rubber latex. Iranian Polymer Journal, 24, 901-909 (2015). https://doi.org/10.1007/s13726-015-0382-8

[16] Lehman N., Yung-Aoon W., Songtipya L., Johns J., Saetung N., Kalkornsurapranee E.: Influence of functional groups on properties of styrene grafted NR using glutaraldehyde as curing agent. Journal of Vinyl and Additive Technology, 25, 339-346 (2019).

https://doi.org/10.1002/vnl.21700 
[17] Kalkornsurapranee E., Yung-Aoon W., Songtipya L., Johns J.: Effect of processing parameters on the vulcanisation of natural rubber using glutaraldehyde. Plastics, Rubber and Composites: Macromolecular Engineering, 46, 258-265 (2017). https://doi.org/10.1080/14658011.2017.1323610

[18] Baur J. F., Ensminger G. L.: The association of official analytical chemists (AOAC). Journal of the American Oil Chemists' Society, 54, 171-172 (1977). https://doi.org/10.1007/BF02670789

[19] Nun-anan P., Wisunthorn S., Pichaiyut S., Vennemann N., Nakason C.: Novel approach to determine non-rubber content in Hevea brasiliensis: Influence of clone variation on properties of un-vulcanized natural rubber. Industrial Crops and Products, 118, 38-47 (2018). https://doi.org/10.1016/j.indcrop.2018.03.011

[20] Barbe A., Bökamp K., Kummerlöwe C., Sollmann H., Vennemann N., Vinzelberg S.: Investigation of modified SEBS-based thermoplastic elastomers by temperature scanning stress relaxation measurements. Polymer Engineering and Science, 45, 1498-1507 (2005). https://doi.org/10.1002/pen.20427

[21] Nawamawat K., Sakdapipanich J. T., Ho C. C.: Effect of deproteinized methods on the proteins and properties of natural rubber latex during storage. Macromolecular Symposia, 288, 95-103 (2010). https://doi.org/10.1002/masy.201050212

[22] Dafader N. C., Haque M. E., Akhtar F., Ahmad M. U.: Study on grafting of different types of acrylic monomers onto natural rubber by $\gamma$-rays. Radiation Physics and Chemistry, 75, 168-172 (2006). https://doi.org/10.1016/j.radphyschem.2005.04.002
[23] Smitthipong W., Tantatherdtam R., Rungsanthien K., Suwanruji P., Klanarong S., Radabutra S., Thanawan S., Vallat M. F., Nardin M., Mougin K., Chollakup R.: Effect of non-rubber components on properties of sulphur crosslinked natural rubbers. Advanced Materials Research, 844, 345-348 (2014).

https://doi.org/10.4028/www.scientific.net/AMR.844.345

[24] Junkong P., Cornish K., Ikeda Y.: Characteristics of mechanical properties of sulphur cross-linked guayule and dandelion natural rubbers. Royal Society of Chemistry, 7, 50739-50752 (2017). https://doi.org/10.1039/C7RA08554K

[25] Chatterjee T., Vennemann N., Naskar K.: Temperature scanning stress relaxation measurements: A unique perspective for evaluation of the thermomechanical behavior of shape memory polymer blends. Journal of Applied Polymer Science, 135, 45680/1-45680/11 (2017). https://doi.org/10.1002/app.45680

[26] Wu M., Heinz M., Vennemann N.: Investigation of unvulcanized natural rubber by means of temperature scanning stress relaxation measurements. Advanced Materials Research, 718-720, 117-123 (2013).

https://doi.org/10.4028/www.scientific.net/AMR.718-720.117

[27] Kalkornsurapranee E., Yung-Aoon W., Thongnuanchan B., Thitithammawong A., Nakason C., Johns J.: Influence of grafting content on the properties of cured natural rubber grafted with PMMAs using glutaraldehyde as a cross-linking agent. Advances in Polymer Technology, 37, 1478-1485 (2017). https://doi.org/10.1002/adv.21806 